Tópico de Interesse Geral

\title{
Prototecose: uma doença emergente ${ }^{1}$
}

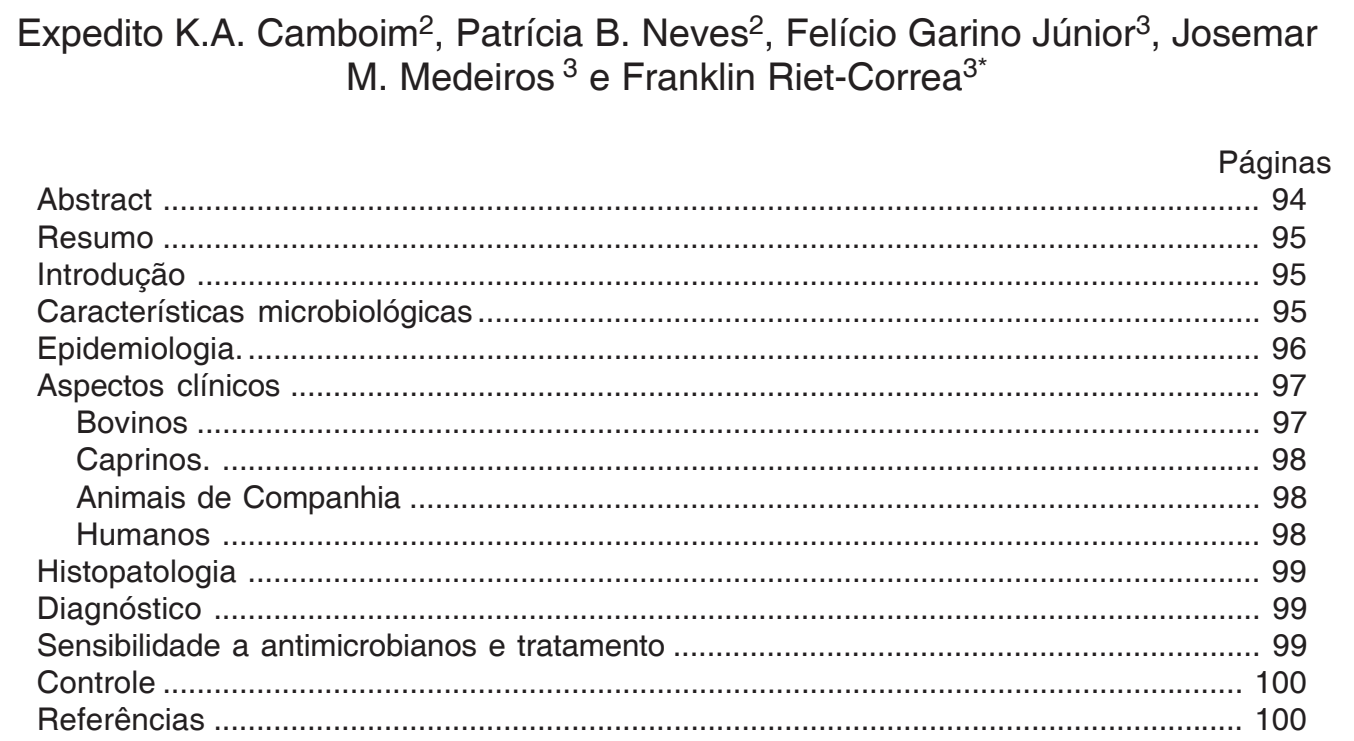

ABSTRACT.- Camboim E.K.A., Neves P.B., Garino Jr F., Medeiros J.M. \& Riet-Correa F. 2010. [Protothecosis: An emergent disease.] Prototecose: uma doença emergente. Pesquisa Veterinária Brasileira 30(1):94-101. Hospital Veterinário, Centro de Saúde e Tecnologia Rural, Universidade Federal de Campina Grande, Campus de Patos, 58700970 Patos, PB, Brasil. E-mail: franklin.riet@pq.cnpq.br

Protothecosis, caused by Prototheca zopfii or $P$. wickerhamii, is an emergent disease of human and animals. In cattle, $P$. zopfii is an important cause of environmental mastitis. In dogs and cats protothecosis is caused mainly by $P$. zopfii, causing cutaneous infections or a systemic form affecting many organs in dogs, and cutaneous infection affecting mainly the skin of the face and nose in cats. In humans, protothecosis, caused mainly by $P$. wickerhamii, occurs in three forms: cutaneous; olecran bursitis; and disseminated. The lesion is usually localized in the site of inoculation in immunocompetent individuals; however, in immunocompromised patients, it can become widespread. Protothecosis caused by $P$. wickerhamii was recently reported in goats causing rhinitis and dermatitis of the face and pinna. This paper reviews microbiologic characteristics and susceptibility to antimicrobials of Prototheca spp., and the epidemiology, clinical signs, pathology, diagnosis, treatment and control of protothecosis.

INDEX TERMS: Prototheca, protothecosis, mastitis, bovines, dogs, cats, goats, human.

\footnotetext{
1 Recebido em 25 de maio de 2009.

Aceito para publicação em 17 de agosto de 2009.

2 Programa de Mestrado em Medicina Veterinária de Ruminantes e Equideos, Centro de Saúde e Tecnologia Rural (CSTR), Universidade
}

\footnotetext{
Federal de Campina Grande (UFCG), Campus de Patos, 58700-000, Patos, PB Brasil.

${ }^{3}$ Hospital Veterinário, CSTR, UFCG, Patos, PB 58700-000. *Autor para correspondência: franklin.riet@pq.cnpq.br
} 
RESUMO.- Prototecose, causada por Prototheca zopfii ou $P$. wickerhamii, é uma doença emergente em animais e humanos. Em bovinos, P. zopfii é uma importante causa de mastite ambiental. Em cães e gatos, a prototecose é causada principalmente por P. zopfii. Em cães, causa infecção cutânea ou uma forma sistêmica envolvendo diversos órgãos. Em gatos, predominam as lesões tegumentares na região da face e plano nasal. No homem, a prototecose, causada principalmente por $P$. wickerhamii, manifesta-se sob três formas: cutânea, articular com bursite do olécrano e sistêmica. Pode ocorrer em indivíduos imunocompetentes, os quais podem apresentar bursite e/ou infecções cutâneas localizadas, ou em indivíduos imunossuprimidos, nos quais a enfermidade pode ser disseminada e/ou com envolvimento visceral. A prototecose causada por $P$. wickerhamii foi descrita recentemente em caprinos como causa de rinite afetando o vestíbulo nasal, união mucocutânea, pele da face e orelha. Nesta revisão são abordadas as características microbiologias e susceptibilidade a antimicrobianos do agente, e a epidemiologia, sinais clínicos, patologia, diagnóstico, tratamento e controle da prototecose em animais domésticos e no homem.

TERMOS DE INDEXAÇÃO: Prototheca, prototecose, bovinos, mastite, cães, gatos, caprinos, humanos.

\section{INTRODUÇÃO}

O gênero Prototheca foi inicialmente descrito por Wilhelm Krueger, em 1894, como um grupo de microrganismos isolados da seiva de algumas árvores (Pore et al. 1983). De acordo com suas características estruturais, histológicas e reprodutivas, esses agentes foram classificados como algas aclorofiladas com afinidades filogenéticas a Chlorella spp. (Pore et al. 1983). As algas do gênero Prototheca perderam o pigmento clorofila e a capacidade de realizar a fotossíntese, havendo necessidade de fonte heterotrófica de nutrientes, o que pode ter conferido potencial patogênico a esse microrganismo (Costa et al. 1998). O gênero está presente na natureza, principalmente em habitats ricos em matéria orgânica (Pore et al. 1983); é composto de cinco espécies, P. zopfii, P. wickerhamii, P. ulmea, P. stagnora e $P$. blaschkeae (Roesler et al. 2006). P. zopfii e P. wickerhamii são patogênicas e têm sido associadas a infecções no homem e em animais na Europa, na Ásia, na África, na Austrália e nas Américas (Costa et al. 1997, Hollingsworth 2000, Corbellini et al. 2001, Bexiga et al. 2003, Buzzini et al. 2004, Hosaka \& Hosaka 2004, Lass-Flörl \& Mayr 2007, Macêdo et al. 2008, Salvadori et al. 2008). A prototecose é uma zoonose emergente em animais e humanos (Costa et al. 1999, Lass-Flörl \& Mayr 2007).

O presente trabalho objetiva revisar as características microbiológicas, epidemiologia, sinais clínicos, patologia, diagnóstico, tratamento e controle da prototecose em animais domésticos e no homem.

\section{CARACTERÍSTICAS MICROBIOLÓGICAS}

Os microrganismos do gênero Prototheca são algas unicelulares e imóveis de distribuição mundial. Foram isola- dos a partir de água do mar, de lagos e rios, da seiva de árvores, de lama, de espécies animais, como porcos, ratos, bovinos, cães e gatos, e de leite e fezes (Pore et al. 1983). Utilizam glicose como fonte de carbono, sais de amônio e proteínas como fonte de nitrogênio, além de necessitarem de oxigênio e tiamina para o crescimento (Pore 1985, 1998).

A reprodução é assexuada por septação interna (endosporulação). Durante o processo reprodutivo, a célula-mãe, denominada esporângio, forma entre duas a dezesseis células-filhas, denominadas endósporos. Os endósporos permanecem dentro do esporângio, envoltos por uma cápsula trilaminar de esporopolenina, que quando se rompe os libera, quando então se desenvolvem e reiniciam o ciclo das células de origem (Pore 1985, Jánosi et al. 2001).

As algas do gênero Prototheca crescem em condições de aerobiose. De acordo com o meio de cultura empregado, $\mathrm{o}$ isolamento do microrganismo pode variar entre dois e sete dias, em intervalos de temperatura de $25^{\circ} \mathrm{C}$ a $37^{\circ} \mathrm{C}$. Em ágar sangue ovino a $5 \%$ formam colônias pequenas, brancoacinzentadas (Fig.1A) (Ribeiro et al. 1998, Vargas et al. 1998). No ágar Sabouraud formam colônias de tonalidade branca a dourada, entre 1 a 2 mm de diâmetro (Pore 1985, Jánosi et al. 2001). Após 72 a 96 horas de incubação, as colônias apresentam diâmetro variável entre 3 e $6 \mathrm{~mm}$ e bordas irregularmente onduladas com elevação central (Fig.1B) (Brito \& Veiga 1997, Bexiga et al. 2003, Carneiro et al. 2007).

A morfologia da alga pode ser avaliada mediante colorações de Gram (Fig.1D) (Vargas et al. 1998), Giemsa, Panótico (Ribeiro et al. 1998), além de outras colorações específicas para fungos, como o azul de algodão, em que se observam os esporangiosporos dentro de um esporângio. No caso da $P$. wickerhamii espangiosporos se distribuem ao redor de um espangiosporo central dando a célula um aspecto de mórula, flor de margarida ou framboesa (Fig.1C) (Vargas et al. 1998, Dipersio 2001). Por outro lado, quando corados com azul de metileno ou cristal violeta, visualizam-se apenas corpúsculos relativamente grandes, ovóides ou globosos, sem delimitação dos esporangiosporos (Brito \& Veiga 1997, Filippsen et al. 1999). As células de $P$. wickerhamii são esféricas e medem de 2,5 a $13 \mu \mathrm{m}$ de diâmetro, enquanto as células de $P$. zopfii podem ser esféricas ou ovais, com tamanho variando de 4,5 a 25 um de diâmetro (Pore 1985).

As espécies são diferenciadas com base nas características morfo-tintoriais e em testes de assimilação de carboidratos e álcoois (Quadro 1). Nas provas de fermentação, P. zopfii é positiva para glicose, frutose, 2-propanol,

Quadro 1. Testes de assimilação de carboidratos e álcool para a diferenciação de espécies do gênero Prototheca

\begin{tabular}{lccccc}
\hline \multicolumn{1}{c}{ Espécies } & \multicolumn{5}{c}{ Assimilação } \\
\cline { 2 - 5 } & Frutose & Galactose & 1-Propanol & Trealose \\
\hline Prototheca moriformis & + & - & $+/ \mathrm{v}^{\mathrm{a}}$ & - \\
P. stagnora & + & + & $+/ \mathrm{v}$ & - \\
P. ulmea & - & - & - & - \\
P. wickerhamii & + & + & - & + \\
P. zopfii & + & - & + & -
\end{tabular}

$\mathrm{a}=$ variável. 


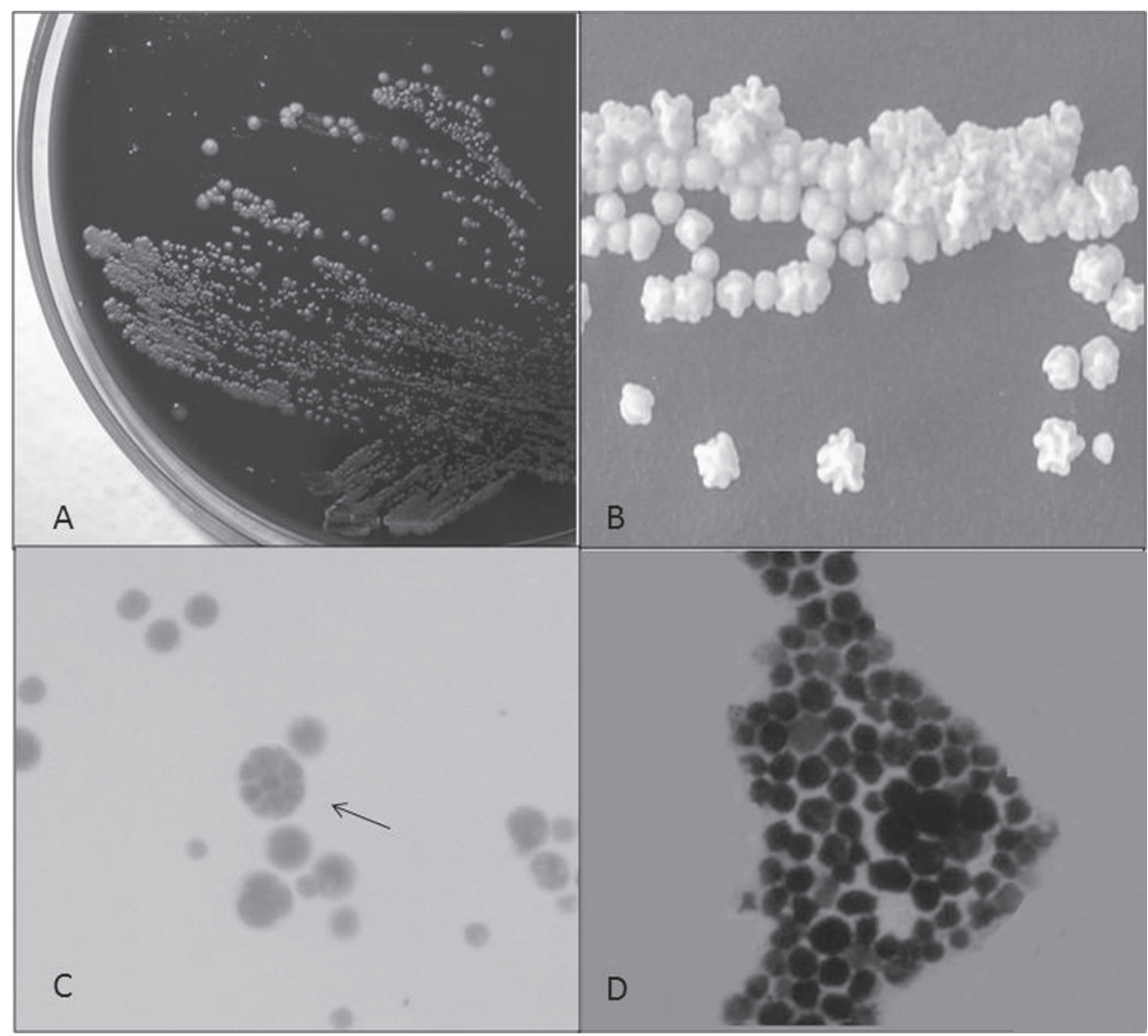

Fig.1. Prototheca wickerhamii. (A) Colônias de Prototheca wickerhamii em ágar sangue ovino $5 \%$ e (B) em agar Sabouraud dextrose. (C) Morfologia em azul de algodão, observam-se esporangiosporos dentro de um esporângio, que dá o aspecto de mórula. (D) Morfologia da alga em coloração de Gram.

acetato $(\mathrm{pH} 5,0)$, glicerol e negativa para lactose, sacarose, trealose, xilose e manose. P. wickerhamii assimila glicose, galactose, trealose e levulose, mas não assimila maltose, sacarose, lactose, xilose, dulcitol, rafinose, inositol, melibiose, adonitol, eritritol, propanol, salisina e amido (Pore 1998).

\section{EPIDEMIOLOGIA}

Algas do gênero Prototheca estão distribuídas no ambiente, principalmente em locais úmidos e ricos em matéria orgânica, os quais permitem a disseminação e perpetuação do agente. Em ecossistemas aquáticos, como rios e bebedouros, com baixa concentração de nutrientes, as espécies sobrevivem sem crescimento populacional. A partir desses locais, a alga pode ser ingerida por animais e ser disseminada no ambiente pela eliminação através das fezes de vacas, bezerros e de animais silvestres (Pore et al. 1983, Costa et al. 1997, Costa et al. 2001). Pore et al. (1983) e Costa et al. (2000) verificaram que as principais fontes de disseminação para $P$. zopfii nas propriedades leiteiras são bezerros, vacas em lactação, suínos, roedores, cães e gatos.

A presença de Prototheca spp. nas feces de animais foi relatada após consumo de alimentos contaminados, pois os esporângios passam livremente através do trato digestivo (Pore \& Shashan 1988). Este fato foi constatado por Costa et al. (2000) e Yamamura et al. (2008) onde bezerros alimentados com leite de vacas com mastite por Prototheca spp. liberam o agente através das feces.

Do gênero Prototheca, somente $P$. zopfii e $P$. wickerhamii são relatadas como causa de infecção em humanos e animais (Costa et al. 1997, Thiele \& Bergmann 2002, Van Bezooijen \& Newling 2002, Stenner et al. 2007, Salvadori et al. 2008).

Em um surto de mastite bovina, Costa et al. (1997) isolaram $P$. zopfii de amostras de fezes de bezerros e de vacas em lactação, teteiras, amostras de água de bebedouro, esgoto e do solo da pastagem, evidenciando o caráter ambiental da infecção. A descarga fecal aumenta a contaminação ambiental, favorecendo a transmissão do agente para outros hospedeiros. Pore \& Shahan (1988) isolaram Prototheca spp. de feces de suínos e ratos; estes últimos podem servir de vetores contaminando a alimentação dos animais. Costa et al. (1998) descreveram o isolamento de $P$. zopfii das fezes de um proprietário rural, após consumo de queijo fresco produzido com leite de vacas com mastite por $P$. zopfii. O paciente apresen- 
tou distúrbio gastrintestinal, sugerindo que o microrganismo pode causar infecção em indivíduos saudáveis que consumam alimentos contaminados.

$\mathrm{O}$ isolamento destes microrganismos de amostras de esgoto demonstra a adaptação a ambientes modificados pelo homem, que contêm nutrientes necessários para o desenvolvimento e multiplicação (Costa et al. 1997). Prototheca spp. possivelmente não se multiplica no trato digestivo dos animais, a sua multiplicação ocorre no meio ambiente rico em matéria orgânica e úmido. A alga também foi encontrada em alimentos úmidos deteriorados, podendo constituir-se em fonte de infecção para as diversas espécies animais que venham a consumi-los (Pore \& Shahan 1988).

Prototecose foi descrita em algumas espécies animais assumindo vários aspectos clínicos, sendo a mastite bovina a que ocorre com maior frequência (Costa et al. 1996), seguida pela infecção em cães (Jagielski \& Lagneau 2007). No Brasil, a apresentação clínica mais estudada é a mastite bovina, devido aos prejuízos causados e à ausência de terapia efetiva (Costa et al. 1996, 1997).

$P$. zopfii foi diagnosticada em rebanhos leiteiros onde ocorreram surtos de mastite. $\mathrm{O}$ isolamento de Prototheca de teteiras indica que a deficiência na higiene e manutenção do equipamento de ordenha pode ser responsável pela transmissão do microrganismo, mesmo após a imersão das mesmas em solução clorada (Costa et al. 1997).

Há relatos de introdução da enfermidade mediante a aquisição de animais infectados em rebanhos sem histórico de mastite por Prototheca spp. (Brito \& Veiga 1997).

A doença foi relatada recentemente em caprinos (Macêdo et al. 2008) e até o momento não foi descrita em búfalos, ovinos e equinos. A alga pode ser isolada de feces de suínos, embora pareça não apresentar patogenicidade para a espécie (Siqueira et al. 2008).

Entre os relatos de prototecose em cães e gatos, observa-se que os autores não descrevem dados epidemiológicos, principalmente, no tocante à origem dos animais e ao ambiente em que vivem (Siqueira et al. 2008).

Infecção da pele por Prototheca spp. no homem e em cães e gatos é comumente o resultado da contaminação de ferimentos ou áreas traumatizadas (Dipersio 200l, Thiele \& Bergmann 2002, Jagielski \& Lagneau 2007), mas a possibilidade de mecanismo de transmissão por insetos não pode ser descartada (Pore et al. 1983, Pore \& Shashan 1988).

O período de incubação geralmente não é conhecido, mas em situações onde a lesão primária é relatada, acredita-se que seja de aproximadamente duas semanas (Dipersio 200l).

A prototecose humana é rara, mas observa-se o aumento da incidência em pacientes imunocomprometidos. Até 2007, 117 casos foram relatados em todo o mundo, dos quais $66 \%, 19 \%$ e $15 \%$ foram associados à infecção cutânea, sistêmica e bursites, respectivamente. Entre os indivíduos com infecção disseminada, 59\% obtiveram cura (Lass-Flörl \& Mayr 2007). O risco de contrair a doença está associado à atividade rural e de jardinagem, comprovando a importância do ambiente para a infecção (Siqueira et al. 2008).

Prototheca spp. resiste ao tratamento com cloro, tratamento de esgoto e a digestão intestinal e isso contribui para sua persistência em esgotos, disseminação por animais domésticos e permanência no meio ambiente (Pore 1983). Também é resistente à pasteurização do leite, tanto lenta quanto rápida, representando um problema para o consumo de leite e de seus produtos derivados, aumentando o potencial zoonótico (Melville et al. 1999). A resistência apresentada por estes microrganismos é explicada pela presença da esporopolenina, um componente da parede celular que confere resistência a vários agentes físicos e químicos (Atkinson et al. 1972). A esporopolenina é um polímero resistente à acetólise, responsável pela resistência da parede celular, encontrada no grão de pólen de angiospermas e gimnospermas, e também nos esporos de pteridófitas, fungos e algas (Gunnison \& Alexander 1975, Dickinson 1976).

\section{ASPECTOS CLÍNICOS}

\section{Bovinos}

Microrganismos do gênero Prototheca têm sido considerados como causa emergente de mastite em bovinos. A distribuição ubíqua do agente favorece a infecção ascendente da glândula mamária, caracterizando uma mastite ambiental (Bexiga et al. 2003, Buzzini et al. 2004, Vaz et al. 2005).

Os animais infectados podem apresentar mastite subclínica ou clínica (aguda ou crônica), sendo o quadro crônico a forma predominante, e a principal espécie envolvida é P. zopfii (Costa et al. 1997, Filippsen et al. 1999, Corbellini et al. 2001, Bexiga et al. 2003, Vaz et al. 2005, Bueno et al. 2006a, Yamamura et al. 2007).

Em animais infectados, a infecção pode persistir no período seco ou ocorrerem novas infecções que não permitem a regeneração adequada da glândula mamária, comprometendo a próxima lactação (Corbellini et al. 2001). A eliminação do agente no leite ocorre de forma intermitente, tornando difícil a detecção de todos os animais infectados (Costa et al. 1996, 1997).

Casos esporádicos de mastite por Prototheca spp. podem ocorrer mesmo em rebanhos com bom manejo; já a forma endêmica está relacionada com condições inadequadas de higiene e alta contaminação ambiental (Costa et al. 1997, Yamamura et al. 2007).

O quadro subclínico se caracteriza pela baixa produção de leite e elevada contagem de células somáticas (CCS) (Bexiga et al. 2003, Buzzini et al. 2004). No entanto, podem ocorrer mastites com CCS baixa (Bueno et al. 2006a). Os animais com infecções subclínicas podem apresentar alterações na composição do leite, podendo haver diminuições nos teores de gordura, lactose e sólidos totais. Este decréscimo pode ser devido à degradação do glicerol e da glicose e por causa do dano no tecido glandular (Bueno et al. 2006b). 
O quadro clínico agudo ocorre principalmente em surtos da enfermidade e se caracteriza pela acentuada redução da produção de leite, podendo ocorrer intenso processo inflamatório do úbere, com secreção glandular apresentando grumos e aspecto sero-purulento ou aquoso (Brito \& Veiga 1997, Bexiga et al. 2003, Bueno et al. 2006a, Yamamura et al. 2007). As alterações crônicas consistem no aumento da consistência do tecido glandular e alterações do leite (Langoni et al. 1995, Vaz et al. 2005, Bueno et al. 2006a).

Um caso de prototecose disseminada causada por $P$. Zopfii foi descrito em uma vaca. A disseminação ocorreu, provavelmente, pela imunosupressão causada pelo uso prolongado de corticóides e antibióticos para tratamento de retenção de placenta e mastite concomitantes. Do foco de infecção inicial na glândula mamária houve disseminação do agente por via hematógena para o coração, pulmões, rins, língua e diafragma (Taniyama et al. 1994).

\section{Caprinos}

A enfermidade em caprinos foi relatada pela primeira vez na região semiárida do estado da Paraíba, Nordeste do Brasil (Macêdo et al. 2008). O animal apresentava perda de peso progressiva, dispnéia inspiratória, estertores e dermatite com nódulos proeminentes na junção mucocutânea das narinas. Não apresentava evidência de doença pré-existente ou imunossupressão. As lesões se estendiam até o vestíbulo nasal, obstruindo a passagem nasal e resultando em severos sinais respiratórios. $\mathrm{O}$ animal apresentou nódulos amarelados, com cerca de $3 \mathrm{~cm}$ de diâmetro no tecido subcutâneo acima do osso nasal. A mucosa do vestíbulo nasal apresentava-se ulcerada com superfície fibrinonecrótica, que se estendia desde a extremidade as narinas até as conchas nasais. $\mathrm{O}$ agente foi identificado histologicamente como $P$. wickerhamii.

Recentemente, um novo caso de prototecose por $P$. wickerhamii, com características muito semelhantes ao anterior, foi observado no semiárido da Paraíba, o que sugere que, em caprinos, a prototecose apresenta uma forma nasal característica. São desconhecidas as condições epidemiológicas nas quais ocorre a doença, mas é provável que os animais se infectem em açudes com pouca água e muita matéria orgânica (Camboim 2009).

\section{Animais de companhia}

A prototecose em cães e gatos é causada, principalmente, por $P$. zopfii. Apresenta-se sob diferentes manifestações clínicas (cutânea, ocular e entérica), no entanto, a colite hemorrágica é a manifestação clínica mais freqüente, sugerindo que a via oral representa a principal forma de infecção nesta espécie (Cook Jr et al. 1984, Hollingsworth 2000, Hosaka \& Hosaka 2004, Stenner et al. 2007, Salvadori et al. 2008, Siqueira et al. 2008). Em gatos, predominam as lesões tegumentares na região da face e plano nasal. As lesões se caracterizam por nódulos, úlceras, crostas exsudativas e rinite (Dillberger et al. 1988, Ginel et al. 1997, Pérez et al. 1997, Siqueira et al. 2008).
Infecção sistêmica, após uso de terapia imunossupressiva, é relatada em cães com sinais clínicos sugestivos de comprometimento de diversos órgãos como pulmões, baço, fígado, trato digestório, olhos, língua e linfonodos (Pressler et al. 2005, Tsuji et al. 2006), causando diarréia (Hosaka \& Hosaka 2004, Stenner et al. 2007, Salvadori et al. 2008, Sapierzynski \& Jaworska 2008), sinais nervosos (Hollingsworth 2000, Stenner et al. 2007, Salvadori et al. 2008), cardiovasculares ou renais (Pressler et al. 2005). Tsuji et al. (2006) diagnosticaram infecção sistêmica em cão causada por $P$. wickerhamii.

\section{Humanos}

No homem, a prototecose é causada principalmente por $P$. wickerhamii e se manifesta de três formas: cutânea, articular e sistêmica, com curso agudo ou crônico. A infecção pode ocorrer em indivíduos imunocompetentes, os quais podem apresentar bursite e/ou infecções cutâneas localizadas, ou em indivíduos imunossuprimidos, nos quais a enfermidade pode ser disseminada (Thiele \& Bergmann 2002, Lass-Flörl \& Mayr 2007).

A forma cutânea é a mais observada e a porta de entrada é a pele traumatizada e feridas infectadas por outros agentes (Thiele \& Bergmann 2002, Lass-Flörl \& Mayr 2007). As lesões têm desenvolvimento lento e não curam espontaneamente; acometem a pele e tecido subcutâneo, principalmente de locais expostos do corpo como cabeça, pescoço e extremidades. A aparência é variável e inclui placas eritematosas, pápulas, crostas, nódulos, úlceras, granulomas cutâneos e erupções eczematosas (Dipersio 200l, Follador et al. 2001, Thiele \& Bergmann 2002). A infecção, geralmente, permanece em áreas localizadas, contudo, a disseminação pode ser observada em indivíduos debilitados e imunocomprometidos (Jagielski \& Lagneau 2007).

A forma articular apresenta-se principalmente como quadro de bursite do olecrano, que se manifesta por leve sensibilidade, moderado eritema e, ocasionalmente, drenagem. Esta forma da infecção ocorre, geralmente, associada a trauma (Dipersio 200l).

A forma sistêmica é tipicamente oportunista. Ocorre em pacientes com imunossupressão ou doença crônica. Os principais órgãos afetados são pele, tecido subcutâneo, intestino, sangue e baço (Lass-Flörl \& Mayr 2007). Menos frequentemente pode ocorrer meningite (Zhang et al. 2007) ou infecção do trato urinário (Van Bezooijen \& Newling 2002). Em paciente leucêmico após transplante de células tronco, observou-se envolvimento de pulmões, rins, coração e fígado (Lass-Flörl et al. 2004). Em muitos desses relatos são descritos fatores predisponentes como: AIDS, neoplasias, transplante, uso de esteróides, cateterização e intubação endotraqueal prolongada (Long et al. 1990, Dipersio 200I, Thiele \& Bergmann 2002, LassFlörl et al. 2004, Lass-Flörl \& Mayr 2007).

\section{HISTOPATOLOGIA}

No exame histológico, há infiltrado inflamatório granulomatoso, constituído por linfócitos, macrófagos, células 
gigantes e neutrófilos. Ao redor da lesão, há proliferação de tecido fibroso. O mais característico da lesão, principalmente nas colorações especiais para fungos, como ácido periódico Schiff (PAS) e Grocott metanamina de prata (GMS), é a presença de miríades de esporângios, contendo internamente esporangiosporos. Estas estruturas podem estar dentro de macrófagos ou livres entre o exudato. Os esporângios aparecem como estruturas ovais ou esféricas, sem brotamentos e rodeados por uma cápsula ou parede que varia de 7 a $30 \mu \mathrm{m}$. Tanto $P$. zopfii quanto $P$. wickerhamii se reproduzem por septação interna resultando em esporangiosporos infectantes. $P$. zopfii tende a ser maior $(7-30 \mu \mathrm{m})$ que $P$. wickerhamii (3-15 $\mu \mathrm{m})$. É característico de $P$. wickerhamii a presença de esporangiosporos com um endósporo central arredondado, rodeado por uma coroa de endósporos, descrito como semelhantes à mórula, flor de margarida ou framboesa (Fig.2) (Lee et al. 1975, Cook Jr et al. 1984, Ginel et al. 1997; Pérez et al. 1997, Dipersio 200l, Bexiga et al. 2003, Pfaller \& Diekema 2005, Bueno et al. 2006b, Tsuji et al. 2006, Carneiro et al. 2007, Jagielski \& Lagneau 2007, Macêdo et al. 2008).

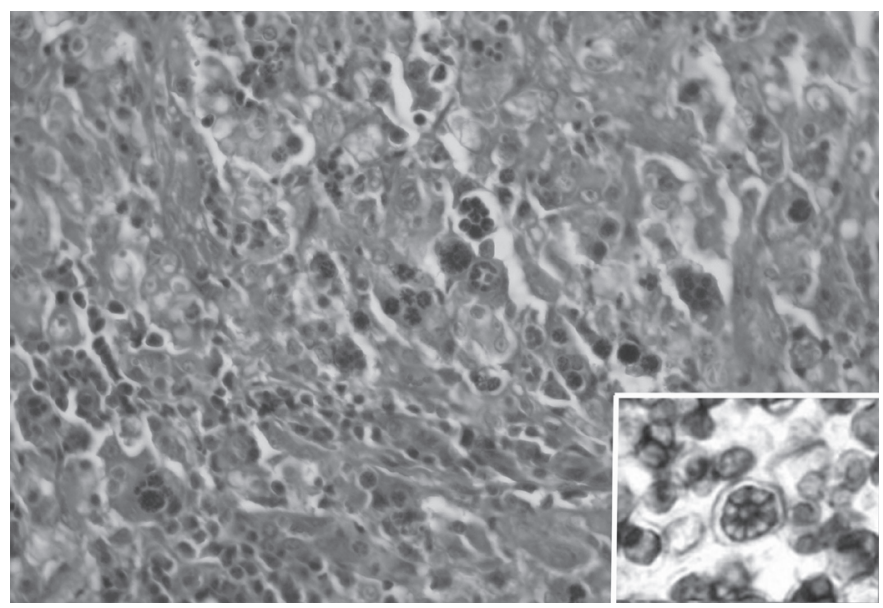

Fig.2. Lesão granulomatosa característica de Prototheca wickerhamii contendo esporângios que variam de 3 a $15 \mu \mathrm{m}$ de diâmetro, algumas com vários esporangiosporos, formando estruturas semelhantes à mórula (centro da figura) ou flor de margarida. Hematoxilina-eosina, obj 20x. Inserido: esporângio com forma de mórula, característico de $P$. wickerhamii, corado pelo Grocott metanamina de prata, obj $40 x$.

\section{DIAGNÓSTICO}

Prototecose é uma doença raramente diagnosticada, provavelmente por ser pouco conhecida. Pode ser confundida com outras enfermidades, principalmente, com infecções fúngicas (Carneiro et al. 2007). Nos tecidos, alguns tipos de fungos podem apresentar aspectos morfológicos semelhantes aos da Prototheca spp. e, macroscopicamente, as colônias brancas cremosas podem ser facilmente confundidas com leveduras (Thiele \& Bergmann 2002).

São importantes para auxiliar no diagnóstico diferencial da prototecose informações sobre dados epidemiológicos, forma de apresentação da doença e histórico de falhas no tratamento. Entretanto, o diagnóstico definitivo só é possível com a utilização de recursos laboratoriais específicos.

No diagnóstico laboratorial, métodos convencionais de cultivo e identificação e histopatologia são as formas mais acuradas (Thiele \& Bergmann 2002). A identificação é feita com base nas características morfológicas da colônia e microscópicas, mediante coloração de esfregaços com tinta nanquim, Gram, azul de metileno e azul de algodão, além das colorações especiais para fungos (Carneiro et al. 2007, Costa et al. 1999). A determinação da espécie é realizada utilizando testes bioquímicos de assimilação de carboidratos e alcoóis, utilizando-se a assimilação de trealose para a diferenciação entre $P$. wickerhamii e $P$. zopfii (Pore 1998). Alternativamente, a diferenciação entre espécies pode ser realizada pelo sistema API $20 \mathrm{C}$ ou API 50C (Padhye et al. 1979).

Técnicas imunológicas, como a imunofluorescência direta, utilizando anticorpos específicos, são indicadas no diagnóstico (Sudman \& Kaplan 1973). O teste imunoenzimático de ELISA (Enzyme Linked Immunosorbent Assay) também pode ser utilizado na detecção de imunoglobulinas específicas ( $\lg A$ e $\lg \mathrm{G} 1$ ), no soro de vacas com mastite, mostrando alta sensibilidade e especificidade (Roesler et al. 2001). O diagnóstico molecular, através da PCR e o sequenciamento de DNA, pode também ser empregado na identificação da prototecose bovina e canina, visando a caracterização e diferenciação de espécies e biótipos de Prototheca spp. (Tsuji et al. 2006, Möller et al. 2007, Osumi et al. 2008).

\section{SENSIBILIDADE A ANTIMICROBIANOS E TRATAMENTO}

Os testes de susceptibilidade in vitro aos antimicrobianos estão entre as principais ferramentas para um tratamento efetivo de doenças infecciosas. Vários estudos têm avaliado o perfil de suscetibilidade de Prototheca spp. frente a antimicrobianos.

Nos testes de susceptibilidade in vitro aos antimicrobianos, tanto $P$. zopfii quanto $P$. wickerhamii têm demonstrado alta resistência à maioria dos antibióticos (Lee et al. 1975, McDonald et al. 1984, Langoni et al. 1995, Vargas et al. 1998, Filippsen et al. 1999, Bexiga et al. 2003, Buzzini et al. 2004).

Nos testes de sensibilidade a antifúngicos, os resultados são bastante controversos, mas na maioria das pesquisas Prototheca spp. têm demonstrado sensibilidade moderada (Segal et al. 1976, McDonald et al. 1984, Bexiga et al. 2003, Buzzini et al. 2004, Lass-Förl et al. 2004, Tortorano et al. 2008).

Em relação ao tratamento de prototecose humana, antifúngicos como cetoconazol, itraconazol, fluconazol e anfotericina B, são as drogas mais comumente usadas, sendo esta última a que apresenta os melhores resultados (Lass-Flörl \& Mayr 2007). Geralmente, administração de antifúngicos e excisão cirúrgica em casos de lesões superficiais tem sucesso terapêutico, embora falhas 
no tratamento não sejam incomuns (Follador et al. 2001, Thiele \& Bergmann 2002, Lass-Flörl et al. 2004, Carneiro et al. 2007, Jagielski \& Lagneau 2007, Lass-Flörl \& Mayr 2007, Zhang et al. 2007).

Em animais, não existe, até o momento, qualquer agente terapêutico eficaz (Bexiga et al. 2003). A resposta à terapia é insatisfatória e pela possibilidade de transmissão para outros animais e o homem não se recomenda o tratamento de animais doentes (Costa et al. 1997, Ginel et al. 1997, Pérez et al. 1997, Vargas et al. 1998, Melville et al. 1999, Bexiga et al. 2003, Stenner et al. 2007).

\section{CONTROLE}

A ação limitada das drogas, a inexistência de medicamentos efetivos e as características biológicas de Prototheca spp. dificultam a preconização de medidas específicas de controle e reforçam a importância da educação sanitária para reduzir a exposição ao agente infeccioso, o risco zoonótico e a disseminação do agente por indivíduos infectados.

O consumo de leite cru, e de seus derivados contaminados, deve ser evitado, principalmente por indivíduos imunocomprometidos ou subnutridos, que são mais suscetíveis à infecção (Costa et al. 1998).

Separar animais doentes, manter o ambiente seco, limpo e exposto à luz solar, usar luvas no manuseio de animais doentes, além de remover materiais orgânicos, são medidas higiênico-sanitárias simples e adequadas que podem diminuir as infecções por microrganismos ambientais (Corbellini et al. 2001, Siqueira et al. 2008). Considerando que o agente pode sobreviver na água, a qualidade desta deve ser sempre observada (Pore et al. 1983, Costa et al. 1998, Corbellini et al. 2001).

O controle de mastite por Prototheca spp. em rebanhos é altamente difícil e o descarte dos animais infectados é indicado uma vez que se tornam portadores; a eficiência terapêutica é baixa, as lesões na glândula mamária são irreversíveis e há risco potencial à saúde humana (Costa et al. 1997). Melville et al. (2002) citam que o nitrato de prata, a clorexidina e o sulfato de cobre apresentam propriedades efetivas contra o microrganismo, podendo ser realizado pre-dipping com clorexidina na profilaxia da mastite.

Deve-se manter monitoramento contínuo do rebanho e seguir as recomendações para controle de mastite, com ênfase na correta rotina de ordenha e higiene ambiental (Costa et al. 1999, Corbellini et al. 2001), cuidados relativos à aquisição de animais e encaminhamento de material suspeito para cultura microbiológica, método mais fidedigno de diagnóstico da prototecose (Brito \& Veiga 1997, Costa et al. 2004, Bueno et al. 2006a).

\section{REFERÊNCIAS}

Atkinson A.W., Gunning B.E.S. \& John P.C.L. 1972. Sporopollenin in the cell wall of Chlorella and other algae: ultrastructure, chemistry and incorporation of 14C-acetate, studied in synchronous cultures. Planta 107:1-32.

Bexiga R., Cavaco L. \& Vilela C.L. 2003. Isolamento de Prototheca zopfii a partir de leite bovino. Revta Port. Ciências Vet. 98:33-37.
Brito M.A.V.P. \& Veiga V.M.O. 1997. Mastite bovina causada por Prototheca zopfii: relato de um caso. Ciência Rural 27(4):681-684.

Bueno V.F.F., Mesquita A.J. \& Dias Filho F.C. 2006a. Prototheca zopfii: importante patógeno na etiologia da mastite bovina no Brasil. Ciência Anim. Bras. 7(3):273-283.

Bueno V.F.F., Mesquita A.J., Neves R.B.S., Souza M.A., Ribeiro A.R., Nicolau E.S. \& Oliveira A.N. 2006b. Epidemiological and clinical aspects of the first outbreak of bovine mastitis caused by Prototheca zopfii in Goiás State, Brazil. Mycopathologia 161:141-145.

Buzzini P., Turchetti B., Facelli R., Baudino R., Cavarero F., Mattalia L., Mosso P. \& Martini A. 2004. First large-scale isolation of Prototheca zopfii from milk produced by dairy herds in Italy. Mycopathologia 158:427-430

Camboim E.K.A. 2009. Prototecose por Prototheca wickerhamii em caprinos. Dissertação de Pós-Graduação em Medicina Veterinária. Centro de Saúde e Tecnologia Rural. Universidade Federal de Campina Grande, Patos, PB. 73p.

Carneiro F.P., Moraes M.A.P., Rebêlo A.M.G. \& Coutinho A.M. 2007. Prototecose cutânea: relato de caso. Revta Soc. Bras. Med. Trop. 40(4):466-468.

Cook Jr J.R., Tyler D.E., Coulter D.B. \& Chandler F.W. 1984. Disseminated protothecosis causing acute blindness and deafness in a dog. J. Am. Vet. Med. Assoc. 184(10):1266-1272.

Corbellini L.G., Driemeier D., Cruz C., Dias M.M. \& Ferreiro L. 2001. Bovine mastitis due to Prototheca zopfii: Clinical, epidemiological and pathological aspects in a Brazilian dairy herd. Trop. Anim. Health Prod. 33:463-470.

Costa E.O., Ribeiro A.R., Melville P.A., Prada M.S., Carciofi A.C. \& Watanabe E.T. 1996. Bovine mastitis due to algae of the genus Prototheca. Mycopathologia 133:85-88.

Costa E.O., Melville P.A., Ribeiro A.R., Watanabe E.T. \& Parolari C.F.F. 1997. Epidemiologic study of environmental sources in a Prototheca zopfii outbreak of bovine mastitis. Mycopathologia 137:33-36.

Costa E.O., Melville P.A., Ribeiro A.R. \& Watanabe E.T. 1998. Relato de um caso de consumo de queijo fresco contaminado com Prototheca spp. Revta Napgama 1(1):9-10.

Costa E.O., Ribeiro A.R., Watanabe E.T., Garino Jr F., Silva J.A.B. \& Junqueira L. 1999. Controle de surto de mastite por Prototheca zopfii em uma propriedade leiteira. Revta Napgama 2(6):12-16.

Costa E.O., Ribeiro A.R., Watanabe E.T., Garino Jr. F. \& Silva J.A.B. 2000. Pesquisa de Prototheca sp. em fezes de bezerros de propriedades que utilizavam o leite de animais com mastite no manejo alimentar dos mesmos em comparação com as que não utilizavam. Revta Napgama 3(1):20-22.

Costa E.O., Garino Jr F., Ribeiro A.R., Watanabe E.T., Silva J.B. \& Diniz L.S. 2001. Participação de animais silvestres na cadeia epidemiológica da mastite bovina por Prototheca zopfii. Revta Napgama 4(4):6-9.

Costa E.O., Ribeiro M.G., Ribeiro A.R., Rocha N.S. \& Nardi Júnior G. 2004. Diagnosis of clinical bovine mastitis by fine needle aspiration followed by staining electron microscopy in a Prototheca zopfii outbreak. Mycopathologia 158:81-85.

Dickinson H.G. 1976. The deposition of acetolysis-resistant polymers during the formation of pollen. Pollen and Spores 18:321-334.

Dillberger J.E., Homer B., Daubert D. \& Altman N.H. 1988. Protothecosis in two cats. J. Am. Vet. Med. Assoc. 192(11):1557-1559.

Dipersio J.R. 2001. Prototheca and protothecosis. Clin. Microbiol. Newsletter 23(15):115-120.

Filippsen L.F., Moreira F.B., Sakashita A.T. \& Bittencourt D.R. 1999. Prevalência da mastite bovina causada por Prototheca zopfii em rebanhos leiteiros, na região norte do Paraná. Ciência Rural 29(1):87-89.

Follador I., Bittencourt A., Duran F. \& Araújo M.G. 2001. Cutaneous protothecosis: Report of the second Brazilian case. Revta Inst. Med. Trop. 43(5):287-290.

Ginel P.J., Pérez J., Molleda J.M., Lucena R. \& Mozos E. 1997. Cutaneous protothecosis in a dog. Vet. Rec. 140(25):651-653. 
Gunnison D. \& Alexander M. 1975. Basis for the resistance of several algae to microbial decomposition. Appl. Microbiol. 29(6):729-738.

Hollingsworth S.R. 2000. Canine protothecosis. Vet. Clin. North Am., Small Anim. Pract. 30(5):1091-1101.

Hosaka S. \& Hosaka M. 2004. A case report of canine protothecosis. J. Vet. Med. Sci. 66(5):593-597.

Jagielski T. \& Lagneau P.E. 2007. General Review: Protothecosis. A pseudofungal infection. J. Mycol. Méd. 17:261-270.

Jánosi S., Ratz F., Szigeti G., Kulcsar M., Kerenyi J., Laukó T., Katona F. \& Huszenicza G. 2001. Review of the microbiological, pathological and clinical aspects of bovine mastitis caused by the alga Prototheca zopfii. Vet. Quart. 23(2):58-61.

Langoni H., Domingues P.F., Funari S.R.C. \& Dias H.L.T. 1995. Prototheca zopfii como agente de mastite bovina. Arq. Bras. Med. Vet. Zootec. 47(5):727-732.

Lass-Flörl C., Fille M., Gunsilius E., Gastl G. \& Nachbaur D. 2004. Disseminated infection with Prototheca zopfii after unrelated stem cell transplantation for leukemia. J. Clin. Microbiol. 42(10):4907-4908.

Lass-Flörl C. \& Mayr A. 2007. Human protothecosis. Clin. Microbiol. Rev. 20(2):230-242.

Lee W.S., Lagios M.D. \& Leonards A. 1975. Wound infection by Prototheca wickerhamii, a saprophytic alga pathogenic for man. J. Clin. Microbiol. 2(1):62-66.

Long E.G., Ebrahimzadeh A., Whit E.H., Swisher B. \& Callaway C.S. 1990. Alga associated with diarrhea in patients with acquired immunodeficiency syndrome and in travelers. J. Clin. Microbiol. 28(6):11011104.

Macêdo J.T.S.A., Riet-Correa F., Dantas A.F.M. \& Simões S.V.D. 2008. Cutaneous and nasal protothecosis in a goat. Vet. Pathol. 45:352-354.

McDonald J.S., Richard J.L. \& Anderson A.J. 1984. Antimicrobial susceptibility of Prototheca zopfii isolated from bovine intramammary infections. Am. J. Vet. Res. 45(6):1079-1080

Melville P.A., Watanabe E.T., Benites N.R., Ribeiro A.R., Silva J.A.B., Garino Jr F. \& Costa E.O. 1999. Evaluation of the susceptibility of Prototheca zopfii to milk pasteurization. Mycopathologia 146:79-82.

Melville P.A., Benites N.R., Sinhorini I.L. \& Costa E.O. 2002. Susceptibility and features of the ultrastructure of Prototheca zopfii following exposure to cooper sulphate, silver nitrate and chlorexidine. Mycopathologia 156(1):1-7.

Möller A., Truyen U. \& Roesler U. 2007. Prototheca zopfii genotype 2The causative agent of bovine protothecal mastitis. Vet. Microbiol. 120:370-374.

Osumi T., Kishimoto Y., Kano R., Maruyama H., Onozaki M., Makimura K., Ito T., Matsubara K. \& Hasegawa A. 2008. Prototheca zopfii genotypes isolated from cow barns and bovine mastitis in Japan. Vet. Microbiol. 131:419-423.

Padhye A.A., Baker J.G. \& D'Amato R.F. 1979. Rapid identification of Prototheca species by the API 20C system. J. Clin. Microbiol. 10(4):579-582.

Pérez J., Ginel P.J., Lucena R., Hervás J. \& Mozos E. 1997. Canine cutaneous protothecosis: An immunohistochemical analysis of the inflammatory cellular infiltrate. J. Comp. Pathol. 117:83-89.

Pfaller M.A. \& Diekema D.J. 2005. Unusual fungal and pseudofungal infections of humans. J. Clin. Microbiol. 43:1495-1504.

Pore R.S., Barnett E.A., Barnes Jr W.C. \& Walker J.D. 1983. Prototheca ecology. Mycopathologia 81:49-62.

Pore R.S. 1985. Prototheca taxonomy. Mycopathologia 90:129-139.

Pore R.S. \& Shahan T.A. 1988. Prototheca zopfii: natural, transient occurrence in pigs and rats. Mycopathologia 101:85-88.

Pore R.S. 1998. Prototheca, a yestlike alga, p.883-887. In: Kurtzman C.P. \& Fell J.W. (Eds), The yeasts: A taxonomic study. Elsevier, New York.
Pressler B.M., Gookin J.L., Sykes J.E., Wolf A.M. \& Vaden S.L. 2005. Urinary tract manifestations of protothecosis in dogs. J. Vet. Int. Med. 19(1):115-119.

Ribeiro M.G., Langoni H., Silveira A.M. \& Ruffino S.M. 1998. Mastite bovina por Prototheca zopfii. Relato de caso e revisão de literatura. Rev. Inst. Biol. 60:1-7.

Roesler U., Holger S. \& Hensel A. 2001. Immunodiagnostic identification of dairy cows infected with Prototheca zopfii at various clinical stages and discrimination between infected and uninfected cows. J. Clin. Microbiol. 39(2):539-543.

Roesler U., Möller A., Hensel A., Baumann D. \& Truyen U. 2006. Diversity within the current algal species Prototheca zopfii: a proposal for two Prototheca zopfii genotypes and description of a novel species, Prototheca blaschkeae sp. nov. Int. J. Syst. Evol. Microbiol. 56:14191425.

Salvadori C., Gandini G., Ballarini A. \& Cantile C. 2008. Protothecal granulomatous meningoencephalitis in a dog. J. Small Anim. Pract. 49(10):531-535.

Sapierzynski R. \& Jaworska O. 2008. Protothecosis as a cause of chronic diarrhoea in a dog. Poland J. Sci. 11(3):225-229.

Segal E., Padhye A.A. \& Ajello L. 1976. Susceptibility of Prototheca species to antifungal agents. Antimicrob. Agents Chemother. 10(1):75-79.

Siqueira A.K., Ribeiro M.G. \& Salerno T. 2008. Prototecose em animais de companhia e aspectos da doença no homem. Ciência Rural 38(6):1794-1804.

Stenner V.J., Mackay B., King T., Barrs V.R., Irwin P., Abraham L., Swift N., Lancer N., Bernays M., Hampson E., Martin P., Krockenberger M.B., Bosward K., Latter M. \& Malik R. 2007. Protothecosis in 17 Australian dogs and a review of the canine literature. Med. Mycol. 45(3):249-266

Sudman M.S. \& Kaplan W. 1973. Identification of the Prototheca species by immunofluorescence. Appl. Microbiol. 25:981-990.

Taniyama H., Okamoto F., Kurosowa T., Furuoka H., Kaji Y. \& Matsukawa K. 1994. Disseminated protothecosis caused by Prototheca zopfii in a cow. Vet. Pathol. 31:123-125.

Thiele D. \& Bergmann A. 2002. Mini-review: Protothecosis in human medicine. Int. J. Hyg. Environ. Health 204:297-302.

Tortorano M.A.P., Dho G., Piccinini R., Dapra V. \& Viviani M.A. 2008. In vitro activity of conventional antifungal drugs and natural essences against the yeast-like alga Prototheca. J. Antimicrob. Chemother. 61:1312-1314.

Tsuji H., Kano R., Hirai A., Murakami M., Yanai T., Namihira Y., Chiba J. \& Hasegawa A. 2006. An isolate of Prototheca wickerhamii from systemic canine protothecosis. Vet. Microbiol. 118(3-4):305-311.

Van Bezooijen B.P.J. \& Newling D.W.W. 2002. Protothecosis of the urinary tract. J. Urol. 167:252.

Vargas A.C., Lazzari A., Santurio J.M., Alves S.H., Ferreira G. \& Kreutz L.C. 1998. Isolation of Prototheca zopfii from a case of bovine mastitis in Brazil. Mycopathologia 142:135-137.

Vaz A.K., Carneiro D.M.V.F., Wolff C., Dick W. \& Luciano A.M. 2005. Mastite bovina por Prototheca sp. em Santa Catarina: Relato de Caso. Revta Ciências Agrovet. 4(1):72-75.

Yamamura A.A.M., Muller E.E., Giordano L.G.P., Cosenza M., Silva P.F.N. \& Godoy A. 2007. Isolamento de Prototheca spp. de vacas com mastite, de leite de tanques de expansão e do ambiente dos animais. Semina, Ciências Agrárias, Londrina, 28(1):105-114.

Yamamura A.A.M., Müller E.E., Freire R.L., Freitas J.C., Giordano L.G.P., Toledo R.S. \& Ribeiro M.G. 2008. Fatores de risco associados à mastite bovina causada por Prototheca zopfii. Ciência Rural 38(3):755760.

Zhang Q.Q., Zhu L.P., Weng X.H., Li L. \& Wang J.J. 2007. Meningitis due to Prototheca wickerhamii: Rare case in China. Med. Mycol. 45(1):85-88. 